\title{
Isolation of L. interrogans Serovar Pomona in 14 Human Cases and an African Lion, All with Chronic Leptospirosis
}

\author{
Beatriz Rivas-Sánchez¹, Oscar Velasco-Castrejón'1,2, Jesús Jimenez-Martínez³ \\ ${ }^{1}$ Clínica de Medicina Tropical, Facultad de Medicina, UNAM, Ciudad de México, México \\ ${ }^{2}$ Dirección de Investigación, Hospital General de México, Ciudad de México, México \\ ${ }^{3}$ Facultad de Medicina, UNAM, Ciudad de México, México \\ Email: beatriz_rivas@hotmail.com, beatriz_rivass@yahoo.com.mx
}

How to cite this paper: Rivas-Sánchez, B., Velasco-Castrejón, O. and Jimenez-Martínez, J. (2016) Isolation of L. interrogans Serovar Pomona in 14 Human Cases and an African Lion, All with Chronic Leptospirosis. Open Journal of Medical Microbiology, 6, 158-170. http://dx.doi.org/10.4236/ojmm.2016.64021

Received: July 29, 2016

Accepted: December 18, 2016

Published: December 21, 2016

Copyright (๑) 2016 by authors and Scientific Research Publishing Inc. This work is licensed under the Creative Commons Attribution International License (CC BY 4.0)

http://creativecommons.org/licenses/by/4.0/ (c) (i) Open Access

\begin{abstract}
Depending on its time of evolution, leptospirosis presents two phases: acute and chronic. The chronic leptospirosis is widely accepted in animals and, until recently, this was denied in humans. Since the 1990s, we have studied dozens of cases demonstrating the chronicity of leptospirosis, including an asymptomatic or undetermined form that may remain so throughout life time or may evolve into a definitive chronic disease and/or worsen, becoming severe cases. A fundamental part for its demonstration is the isolation and characterization of the etiologic agent. In this work, the first 14 isolations of Leptospira sp. are reported from human chronic leptospirosis and an African lion diagnosed with chronic leptospirosis, obtained between 2002 and 2006, in urine, blood, and skin microbiopsies. From the 14 isolations from patients with chronic leptospirosis, one of the cases is apparently congenital and two are from patients with chronic asymptomatic leptospirosis. The diagnosis was performed by means of videorecording in darkfield microscopy in blood and urine, specific culture media, and MAT serology. Argentic impregnation and detection of specific antigen by immunostaining in blood were performed in seven patients; in two patients, skin microbiopsies and biopsies were performed. All cases were positive by video-recording in darkfield, one of them MAT was 1:160, and the rest were positive at low titers $(\leq 1: 80)$. The two skin biopsies were positive by argentic impregnation and immunostaining. Eleven isolates were obtained from blood, two from skin, and one from urine. The isolates were characterized by monoclonal antibodies as Leptospira serovar Pomona. L. Pomona is considered of low virulence and high adaptability to the host, and is frequently associated to chronic leptospirosis in animals. In our study, it was the only isolated serovar, including the one isolated from the lion, which would seem the most common one in our country and responsible for a large
\end{abstract}


portion of cases of chronic human leptospirosis.

\section{Keywords}

Chronic Human Leptospirosis, Immunostaining, Leptospira Pomona, Culture, Isolation

\section{Introduction}

Leptospirosis is the zoonosis most widely distributed in the world [1]. Although it is frequent in temperate zones, it is common in tropical and subtropical areas where the temperature and humidity favor the survival of the etiological agent in moist ground and water contaminated with urine of infected animals [2]. Its increasing magnitude is mainly due to the constant increase of outbreaks reported during natural disasters, events of extreme occurrence in jungles and rivers, in recreational places, such as water resorts, and even in urban areas, particularly by the intimate coexistence with pets [3].

The World Health Organization calculates an approximate prevalence of 100,000 annual cases of severe leptospirosis with $1 \%$ mortality. Studies performed by members of the International Society of Leptospirosis indicate a prevalence for severe acute form of 300,000 to 500,000 annual cases, with a mortality rate of $5 \%$ to $20 \%$. Meanwhile, Gouveia et al. have reported a $74 \%$ mortality rate in leptospirosis associated with hemorrhagic pulmonary syndrome [4] [5].

In Mexico, we have observed hundreds of patients who suffer clinical pictures of long and very long evolution characterized by headache, low-grade fever, dark fever syndrome, chronic fatigue, hypersomnia, arthralgia and myalgia especially in the calf muscles, eye pain, lymphadenopathy, anxiety, depression, hematologic disorders, ophthalmologic and intestinal problems, hepatorenal syndrome, and frequent problems in the Central Nervous System (CNS) [6]. In these patients, leptospires are detected in blood, urine, aqueous humor, cerebrospinal fluid (CSF), and other organic fluids by videorecording in darkfield, argentic impregnation, immunostaining by indirect immunofluorescence and immunohistochemistry [7], and in some cases it has been possible to perform electron micrographs of leptospires in peripheral blood [8].

Practically, in all our patients and in the same way as it happens in animals with chronic disease [9], leptospirosis has evolved for long periods of time [10] [11] and present low titers of antibodies, thus we have diagnosed them as chronic leptospirosis (CL) [12], such as it occurs with other spirochetes that produce well-known chronic diseases: borreliosis and syphilis [13] [14] [15].

On the other hand, the isolation of Leptospira sp. is hard to perform during the acute phase and even harder during the chronic phase. From 2002 to 2006, cultures of blood, urine, bone marrow, micro biopsies and skin biopsies were performed in 700 patients with a presumptive diagnosis of CL. Despite positive primary cultures have been ob- 
tained in $82 \%$ of the cases during the first month, these tend to die without achieving Leptospira's adaptation to the specific culture medium [8].

In this work, the first 14 isolations of Leptospira interrogans are reported and their characterization with monoclonal antibodies, obtained between 2002 and 2006, from 14 patients with chronic disease, which constitutes the evidence that was lacking to demonstrate the existence of Chronic Human Leptospirosis (CHL) and its great importance in Mexico. It is also integrated the Leptospira sp. isolate from an African lion (Panthera leo) with CL.

\section{Material and Methods}

Cases. The isolation from 14 individuals is reported. Each patient is took them blood sample by venipuncture in the forearm, a sample of urine, and in two of them that suffered dermatitis, it took a biopsy by punch and microbiopsy with syringe. Detection of antibodies was performed by plate microaglutination (MAT), and the search for leptospires in blood and urine by videorecording in darkfield. Blood smears were performed to 7 cases, performing argentic impregnation by the modified Fontana technique and antigen detection by indirect immunofluorescence (IIF-ag) and immunohistochemistry (IHC). The samples were cultured in specific media. The 12 symptomatic patients were treated with penicillin and/or doxycycline during 3 months. The isolation of Leptospira sp. from an abandoned African lion that was rescued by the corresponding authorities and diagnosed with CL was also included.

Videorecording in Darkfield. DVD digital camcorder (Sony), connected to a monitor (Sony) and mounted on an Axiostar (Zeiss) microscope with ultracondeser darkfield oil was used to search for leptospires in blood, urine, and skin biopsies and microbiopsies. The videorecording was made by observing the samples at $400 \times$ [7].

MAT: This test was performed according to the WHO's [16] norms. Each serum sample was tested against 13 of the most important serovars of Leptospira in Mexico.

Skin biopsy. Biopsies of skin lesions were obtained with a No. 4 punch. Each biopsy was divided into 3 parts, one was cultured in specific medium, another was homogenized using a tissue homogenizer for darkfield observation, and the last was fixed with $10 \%$ formaldehyde and embedded in paraffin for histologic slide preparation, to which argentic impregnation by Warthin-Starry and antigen detection by IHC and IIF-ag were performed.

Skin microbiopsy. The aspirate syringe method was used. Briefly: a hypodermic syringe with a 20 gauge needle containing $1 \mathrm{ml}$ of isotonic saline was used. The needle was carefully inserted into the injured dermis and proceeded to aspirate while the syringe was rotated on its axis. The microbiopsy that stayed in the needle is obtained by entrainment, depositing the saline solution in a tube. Darkfield observation, Warthin-Starry stain, and culture were performed to this microbiopsy.

Culture. Isolation was performed in $3 \mathrm{ml} \mathrm{EMJH}$ medium [17] [18] (DIFCO ${ }^{\mathrm{TM}}$ Leptospira Medium Base EMJH) supplemented with bovine albumin fraction V (Sigma), tween 80 (Sigma), and decomplemented rabbit serum, which were inoculated with one 
or two drops of blood, urine, skin microbiopsy and biopsy previously homogenized. Media were incubated at $28^{\circ} \mathrm{C}$ and checked it once per month for 2 years.

Argentic impregnation. Fontana method and modified Warthin-Starry [16] [19] were used.

IHC and IIF-ag [20] [21]. A polyclonal serum obtained from the inoculation of rabbits with a pool of Icterohaemorrhagiae, Canicola, Pomona, Patoc, Hardjo, and Grippotyphosa serovars. For IHC, a total anti-Ig rabbit serum conjugated to peroxidase was used and developed with diaminobenzidine and hydrogen peroxide was used; for IIF-ag a total anti-Ig rabbit serum conjugated to fluorescein isothiocyanate was used.

Characterization. The obtained isolates were sent to the International Reference Laboratory for Leptospirosis WHO/FAO/OIE in Amsterdam, Holland, where they were characterized by monoclonal antibodies [22].

\section{Results}

The 15 isolate of L. Pomona from 14 humans and an African lion, obtained from 2002 to 2006, the name of the isolate, sex and age of the patient, and clinical picture are shown in Table 1.

Table 1. Clinical picture and time evolution of studied cases.

\begin{tabular}{|c|c|c|c|c|}
\hline & Sex & $\begin{array}{c}\text { Age } \\
\text { (years) }\end{array}$ & Clinical picture & $\begin{array}{c}\text { Evolution } \\
\text { (years) }\end{array}$ \\
\hline 1 & $\mathrm{~F}$ & 84 & $\begin{array}{l}\text { Chronic fatigue, low-grade fever, headache, liver and kidney failure, } \\
\text { clotting problems, bleeding, jaundice, Weil Syndrome. }\end{array}$ & 5 \\
\hline 2 & $\mathrm{~F}$ & $3 / 12$ & Exanthematic injury, vesicular and bullous lesión & Newborn \\
\hline 3 & M & 28 & $\begin{array}{l}\text { Chronic fatigue, low-grade fever, hypersomnia, myalgias, arthralgias, } \\
\text { depression, fistulous lesions in lumbar region. }\end{array}$ & 7 \\
\hline 4 & M & 51 & $\begin{array}{l}\text { Chronic fatigue, headache, eye pain, myalgias, arthralgias, conjunctival } \\
\text { hemorrhage, ecchymoses and purpura. }\end{array}$ & 10 \\
\hline 5 & M & 32 & Asyntomatic (resident doctor who atended to Weil Syndrome patient) & --- \\
\hline 6 & M & 28 & Asyntomatic (nurse who atended to Weil Syndrome patient) & --- \\
\hline 7 & $\mathrm{~F}$ & 29 & $\begin{array}{l}\text { Chronic fatigue, low-grade fever, eye pain, myalgias, petechiae, } \\
\text { ecchymoses, conjunctival icterus. }\end{array}$ & 1 \\
\hline 8 & $\mathrm{~F}$ & 39 & $\begin{array}{l}\text { Low-grade fever, headache, hypersomnia, eye pain, myalgias, } \\
\text { arthralgias, colitis, amaurosis, cerebral confusion. }\end{array}$ & 32 \\
\hline 9 & $\mathrm{~F}$ & 42 & $\begin{array}{l}\text { Chronic fatigue, febrile syndrome, muscle weakness, } \\
\text { jaundice, skin and mucosal bleeding. }\end{array}$ & $>10$ \\
\hline 10 & $\mathrm{~F}$ & 40 & $\begin{array}{l}\text { Febrile syndrome, headache, mucosal bleeding, purpura on abdomen } \\
\text { and lower extremities, chronic diarrhea, abdominal pain, meningismus. }\end{array}$ & 2 \\
\hline 11 & M & 27 & Chronic fatigue, febrile syndrome, hypersomnia, meningismus. & $6 / 12$ \\
\hline 12 & M & 2 & Fever, repeated episodes of pharyngotonsillitis. & 1 \\
\hline 13 & $\mathrm{~F}$ & 44 & $\begin{array}{l}\text { Chronic fatigue, low-grade fever, headache, hypersomnia, eye pain, } \\
\text { hemorrhagic syndrome, jaundice, hepatomegalia, diaphoresis }\end{array}$ & 12 \\
\hline 14 & $\mathrm{~F}$ & 50 & $\begin{array}{l}\text { Chronic fatigue, low-grade fever, headache, hypersomnia, eye pain, } \\
\text { bleeding. }\end{array}$ & 8 \\
\hline 15 & $\mathrm{M}$ & Unknown & $\begin{array}{l}\text { Lion: Fever, musculoskeletal pain, conjunctival icterus, intestinal } \\
\text { bleeding, stomach flu, weight loss, chronic fatigue. }\end{array}$ & $>3 / 12$ \\
\hline
\end{tabular}

F: female, M: male. 
The 14 human isolates of Leptospira sp. were obtained from 6 males (42.8) and 8 females (57.2\%) with ages ranging from a newborn girl to an 84 -year old woman, all belonging to a medium-low socio-economic status. Twelve patients were clinically diagnosed with CL; 4 of these were initially diagnosed with different pathologies (cases 3, 7, 10,11 ) and 2 presented skin lesions (cases 2 and 4). The other 2 cases (5 and 6) were detected during the study of an outbreak and diagnosed with asymptomatic or undetermined CL (Table 2). The most frequent symptoms were: chronic fatigue (57\%), low-grade fever (43\%), headache (36\%), daytime sleepiness (36\%), sore eyeballs (36\%), myalgia (28.5\%), arthralgia (21.5\%), fever (29\%) jaundice (29\%), hemorrhagic problems (50\%), and skin problems (21.5\%). All patients, except for case 2 who is a newborn girl, referred an evolution time of 6 months to 32 years (Table 1).

The lion presented fever, chronic fatigue, gastroenteritis, intestinal bleeding, weight loss, conjunctiva icterus, and muscle and musculoskeletal pain (Table 1).

MAT serology was positive in all cases with the same or lower titers to 1:80, except for case No. 1 which was positive at 1:160, which corresponds to a long-time evolution Weil syndrome that we diagnosed as acute CL (Table 1 and Table 2).

Videorecording in darkfield was also positive in blood and urine (Figure 1) in all cases (100\%). IFI-ag (86\%), IHQ (71.5\%), and argentic impregnation (71.5\%) in blood of the 7 cases in which the detection of leptospires were positive (Table 3, Figure 2, Figure 3). Microbiopsies and biopsies of the 2 studied cases were also positive to these techniques (Figure 4).

Table 2. Leptospira interrogans isolation, sent to Amsterdam, The Netherlands for typifying.

\begin{tabular}{ccccccc}
\hline & Isolation & Year & Isolation year* & Patient & Initial diagnostic & Sample \\
\hline 1 & Veriant & 2002 & 2002 & JCA & Acute Chronic Leptospirosis & Urine \\
2 & Rivepal & 2004 & 2005 & CPL & Chronic Leptospirosis & Exanthematic injury \\
3 & Rivecaz & 2005 & 2006 & ZSC & Extrapulmonary Tuberculosis & Blood \\
4 & Verimol & 2005 & 2006 & MNS & Chronic Leptospirosis & Skin lesion \\
5 & Rivevap & 2005 & 2006 & VPI & Asyntomatic & Blood \\
6 & Veriluma & 2005 & 2006 & JTLM & Asyntomatic & Blood \\
7 & Verimer & 2005 & 2006 & GGM & Classical Dengue & Blood \\
8 & Beriberi & 2005 & 2006 & RSB & Chronic Leptospirosis & Blood \\
9 & Rivemar & 2005 & 2006 & FRMM & Chronic Leptospirosis & Blood \\
10 & Verimata & 2005 & 2006 & GRM & Salmonellosis, non specific & viral illness, Lyme disease \\
11 & Beriveca & 2005 & 2006 & BCB & Fever of unknow origin & Blood \\
12 & Vecorisa & 2002 & 2003 & GCJ & Chronic Leptospirosis & Blood \\
13 & Verilauf & 2003 & 2004 & FTL & Chronic Leptospirosis & Blood \\
14 & Verijua & 2005 & 2006 & HChJ & Chronic Leptospirosis & Blood \\
15 & Veritza & 2005 & 2006 & León & Chronic Leptospirosis & Blood \\
\hline
\end{tabular}

${ }^{*}$ Isolation year, indicates when the isolation was adapted in the culture medium. 


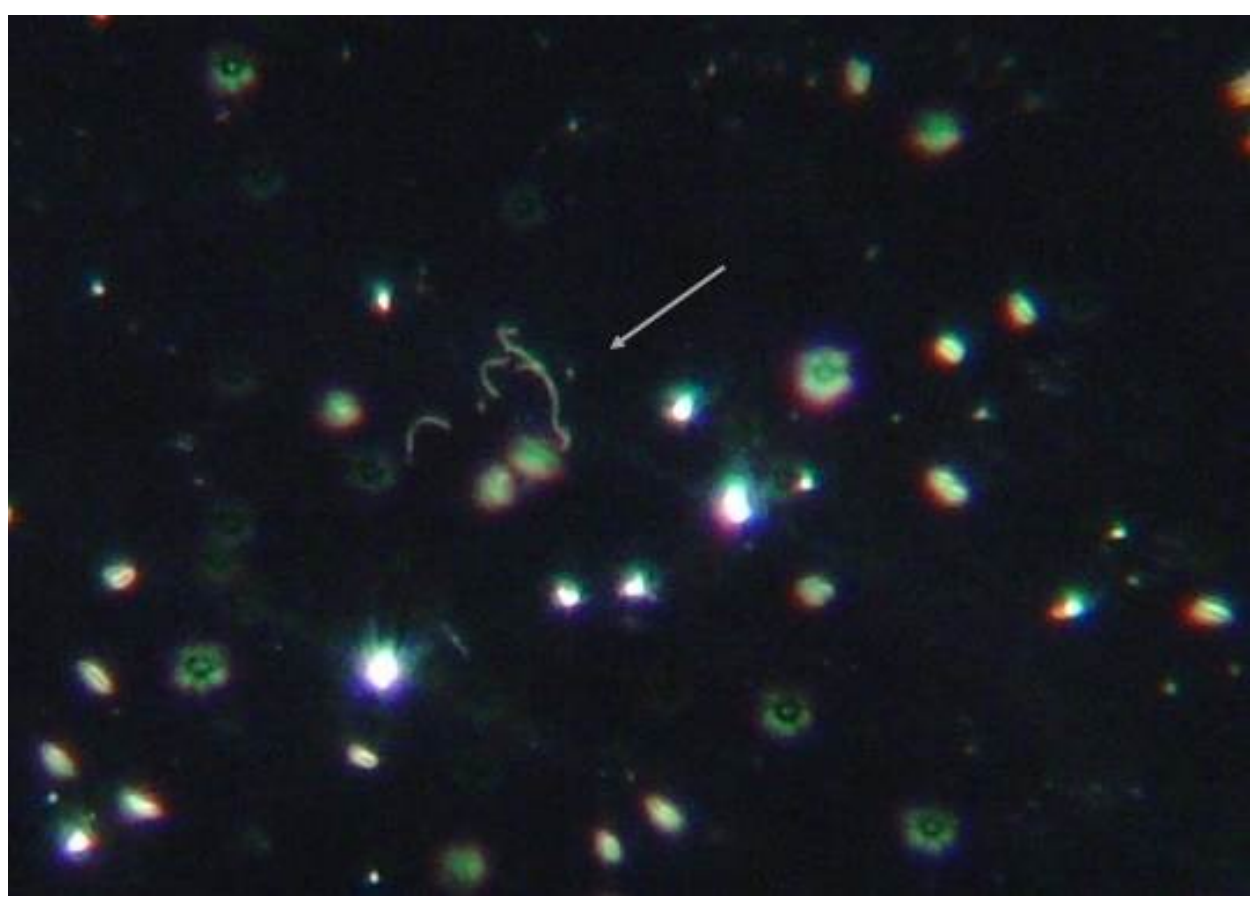

Figure 1. Leptospira in urine, dark field. 400×.

Table 3. Results of initial diagnostic tests of the 15 individuals studied.

\begin{tabular}{|c|c|c|c|c|c|c|c|c|}
\hline \multirow[t]{2}{*}{ Case } & \multirow[t]{2}{*}{ Patient } & \multirow[t]{2}{*}{ Isolation } & \multicolumn{2}{|c|}{ Dark field } & \multirow[t]{2}{*}{ MAT } & \multirow[t]{2}{*}{ IFI-ag } & \multirow[t]{2}{*}{ IHQ } & \multirow[t]{2}{*}{ Argentic stain } \\
\hline & & & Blood & Urine & & & & \\
\hline 1 & JCA & Veriant & + & + & $1: 160$ & + & + & - \\
\hline 2 & CPL & Rivepal & + & + & $1: 40$ & + & - & + \\
\hline 3 & ZSC & Rivecaz & + & + & $1: 40$ & UR & UR & + \\
\hline 4 & MNS & Verimol & + & + & $1: 20$ & + & - & + \\
\hline 5 & VPI & Rivevap & + & + & $1: 80$ & UR & UR & UR \\
\hline 6 & JTLM & Veriluma & + & + & $1: 40$ & UR & UR & UR \\
\hline 7 & GGM & Verimer & + & + & $1: 80$ & UR & UR & UR \\
\hline 8 & RSB & Beriberi & + & + & $1: 40$ & + & + & + \\
\hline 9 & FRMM & Rivemar & + & + & $1: 40$ & UR & UR & UR \\
\hline 10 & GRM & Verimata & + & + & $1: 40$ & UR & UR & UR \\
\hline 11 & $\mathrm{BCB}$ & Beriveca & + & + & $1: 40$ & UR & UR & UR \\
\hline 12 & GCJ & Vecorisa & + & + & $1: 20$ & UR & + & + \\
\hline 13 & FTL & Verilauf & + & + & $1: 80$ & - & + & UR \\
\hline 14 & $\mathrm{HChJ}$ & Verijua & + & + & $1: 20$ & - & + & UR \\
\hline 15 & Lion & Veritza & + & + & $1: 20$ & + & UR & - \\
\hline
\end{tabular}

UR: Unrealized. 


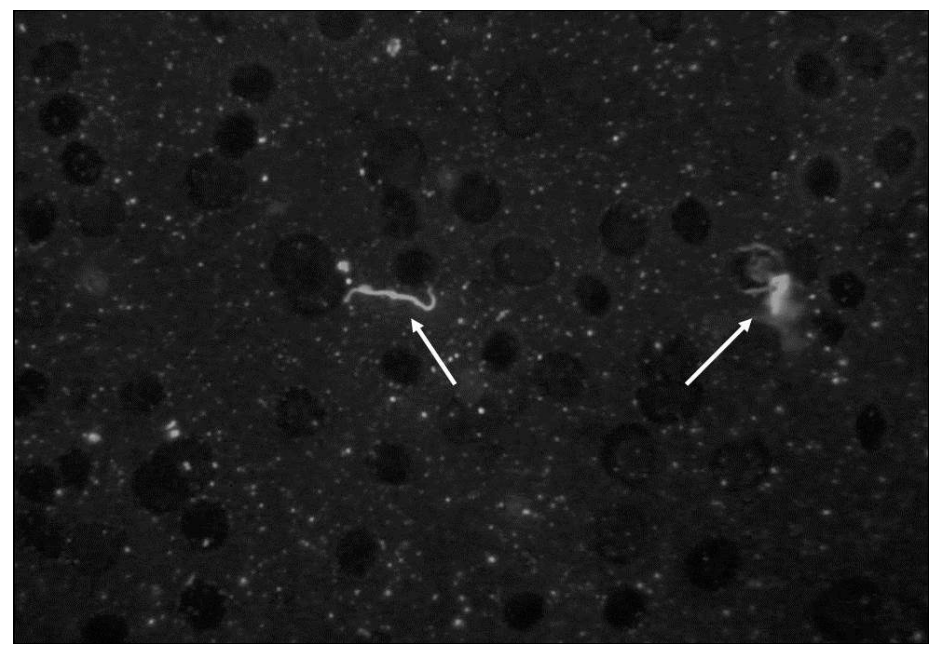

Figure 2. Leptospira antigen deposited over a red blood cell, detected by direct immunofluorescence. 1000x.

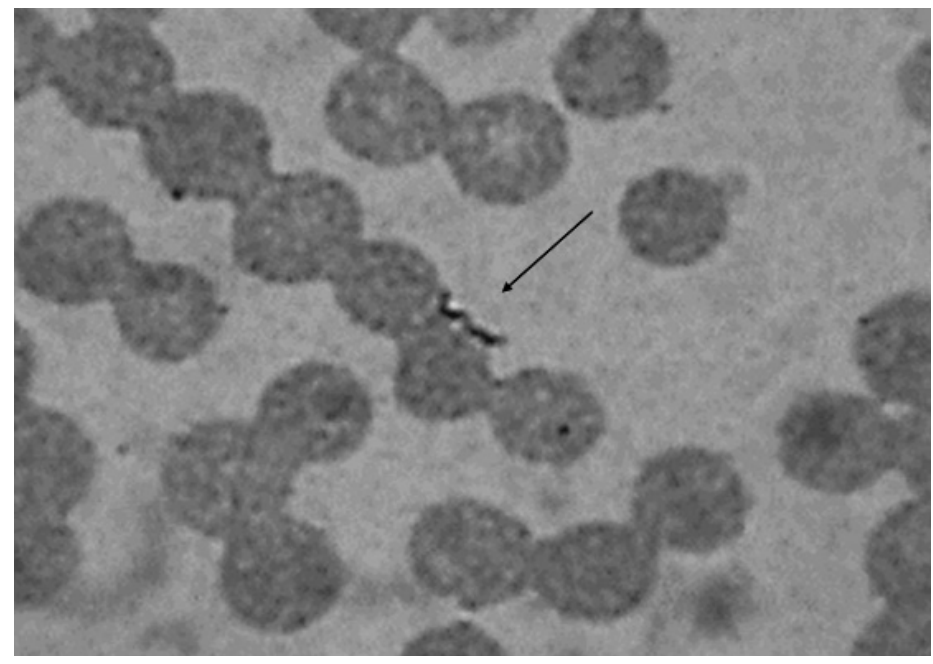

Figure 3. Leptospira in blood. Warthin-Starry stain. 1000x.

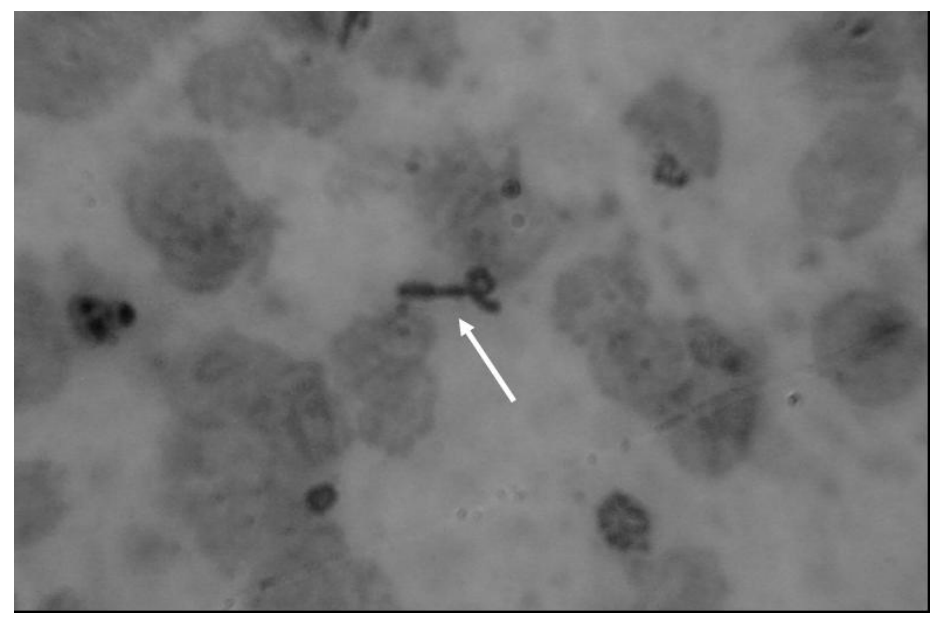

Figure 4. Leptospira in skin microbiopsy. Warthin Starry stain. 1000x. 
Isolations of Leptospira were obtained at different incubation times, between 6 and 18 months, from the 14 human cases and an African lion (Table 2). The 15 isolates were characterized as L. interrogans serovar Pomona by monoclonal antibodies at the International Reference Laboratory for Leptospirosis, OMS/FAO, and OIE, Amsterdam, Holland. Eleven were isolated in blood, one in urine (JCA), and two in skin (MNS and CPL). The isolation of the African lion was obtained in blood (Table 2).

It is important to mention that patients 1 and 2 received penicillin treatment at high doses; unfortunately, the case one died two days after the diagnosis was done. The case two, who had been hospitalized since birth, had an important improvement, but the treatment was abandoned when she was released from the hospital one month later. Cases $3,4,7,8,9,10,11,12,13$, and 14 were treated with doxycycline, $200 \mathrm{mg}$ daily, during three months with a good evolution.

\section{Discussion}

CL is frequent in animals; it has been observed that leptospira remains in renal tubules for months or years after they have recuperated of the acute phase, becoming potential sources of infection [23] [24] [25] [26].

Some clinical manifestations observed in farm animals are miscarriages, uveitis and decrease in the production of milk, and cachexia, which greatly endangers the production of meat of the different types of livestock [23] [24]. It also produces severe illness and death in dogs and zoo animals, including some endangered species (data not published).

The study in these animals and in experimentation animals has demonstrated that $\mathrm{CL}$ is associated with low antibody titers, and the serology titers considered by the international norms lack value in the diagnosis of the disease [10] [26] [27]. For this reason, it is necessary to perform other detection techniques for leptospira as darkfield microscopy, histological techniques such as immunodetection and argentic impregnation, the PCR and cultures.

In humans, it has been observed that $10 \%$ of patients who recuperate in the acute phase continue to present signs and symptoms that persists for months or years [28]. During that time, antibody titers drop to non-significant levels for diagnosis according the official technical norms, thus it is believed that these signs and symptoms are "sequels" of the disease caused by immunologic phenomena [2].

However, there are several reports of endogenous reinfections after 6 months of having presented leptospirosis [11], as well as the isolation of Leptospira interrogans, the detection of antigen by PCR [29] and monoclonal antibodies [30] in cerebrospinal fluid, urine, and aqueous humor months or years after having recuperated from the acute phase. In most cases, negative antibody titers are reported, which confirms the limitations serology has in the diagnosis of long-term evolution leptospirosis (CL) even when the patient has apparently recovered continues excreting leptospires in urine [31].

We have found leptospires in blood, urine, CSF, and in different tissues: kidneys, liver, spleen, bone marrow, brain, skin, etc. through videotaping darkfield microscopy, 
argentic impregnation, IHQ and IIFag in patients suspected of leptospirosis with clinical picture from months or years of evolution [7] [8] [9]. Many of them have been multi-treated by diverse specialists without having a definitive diagnosis despite having subjected their patients to multiple tests. We have even detected leptospiras by electronic microscopy, as in case 7 of the present study (Figure 5).

The most valuable result of this work that leaves no doubt about the etiology of the chronic disease was the isolation of 14 strains of Leptospira interrogans, obtained from blood, urine and/or skin, 11 from chronic patients with an evolution from 6 months to more than 30 years. One of these isolation was from a 3 months old baby who was born with a clinical picture suspicious of congenital syphilis, daughter of a patient who was later diagnosed with CL. The mother of the baby presented a clinical picture characterized by headache, myalgia, arthralgia, eye pain, low-grade fever, colitis, and chronic fatigue, and observation of the bacterium in darkfield, argentic impregnation and positive primary culture.

It is striking the two apparently healthy individuals from whom Leptospira was isolated during a study performed to the medical and paramedical staff after attending a patient with Weil syndrome. Despite seeming logical they would have been infected while handling the sick and her products, due to our experience we believe that they are chronic undetermined patients, Figure 6, and in the same way as it occurs with Chagas disease [32], these patients can become sick many months after. This seems to indicate that some serovars may coexist with their host for a long time without causing apparent damage.

Regarding treatment, although 10 of the patients received doxycycline for three months with a satisfactory evolution, cases $4,8,9,10$, and 11 relapsed one month later, thus they were given treatment for 7 more months with doxycycline and transference factor apparently with good results. However, currently we know that treatment for

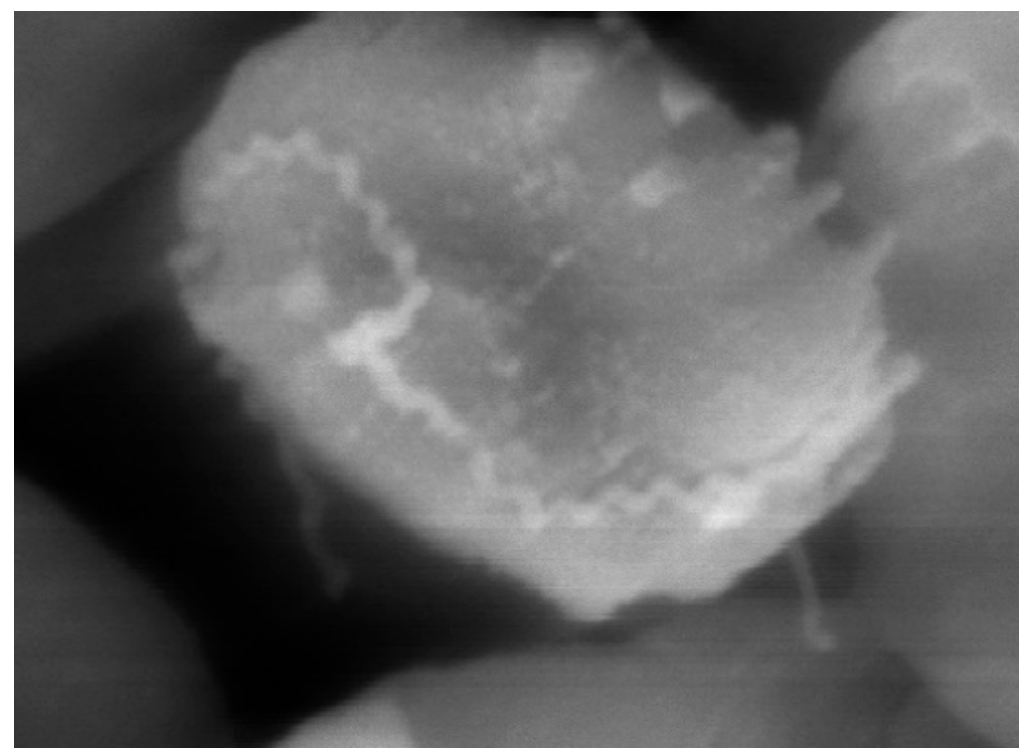

Figure 5. Leptospira over a red blood cell, detected by electronic microscopy. 


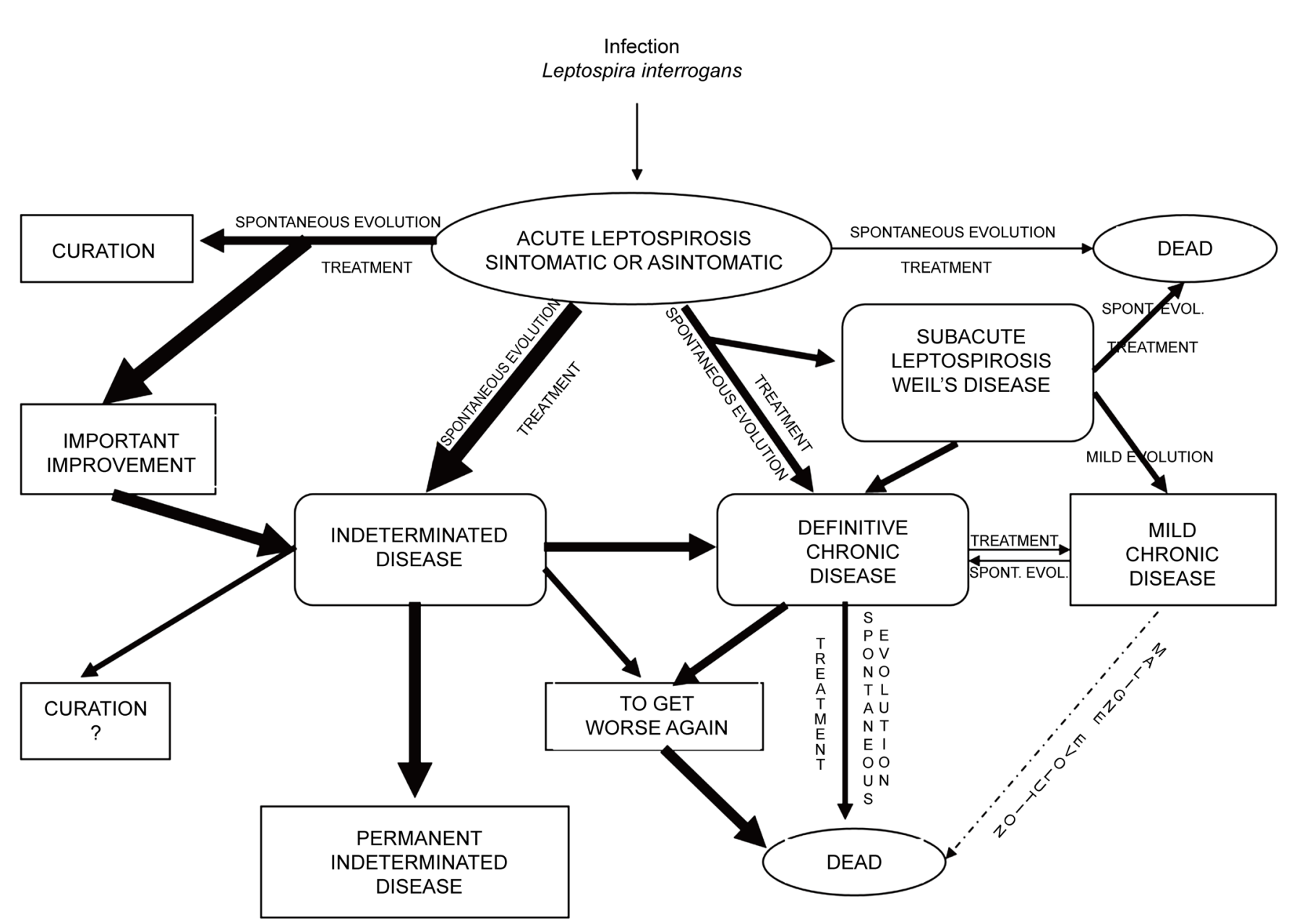

*The width of the arrows suggests the frequency of the phenomenon.

Figure 6. Natural History of Leptospirosis [6].

chronic leptospirosis must be based and penicillin and doxycycline for a long period of time, together with modulators of the immune system, such as transference factor [33] [34].

The isolation from an African lion (Panthera leo) with CL is also presented, which is rescued by a zoo in Mexico City. This suggests that felines, when under stress, are susceptible to the disease.

Surprisingly, all the isolations belong to the Pomona serovar, which is one of the serovars most frequently isolated in animals with CL. This serovar is considered of low virulence and elevated adaptability to its hosts, causing a mild disease and chronic evolution, although susceptibility may increase and cause a serious disease and death.

Probably, L. Pomona is an indicator of the high frequency it circulates in Mexico and the main cause of mild symptoms, considered normal and related to the patient's age and genetic background, and even of symptoms never before attributed to leptospirosis such as migraine, dermatitis, prostatitis, metritis, and particularly colitis, All these symptoms are an example of the undetermined form of LC. 
Another contribution of this work is the waiting time to discard apparently negative cultures, for the universal recommendation is of 16 weeks of incubations. In our case, some of the positive primary cultures achieved total adaptation to the culture medium after 18 months of incubation.

Finally, we believe that the low percentage of isolation from a large number of patients is possibly because leptospires from chronic patients may have a different metabolism from the leptospires isolated from acute cases, therefore they may not develop easily in the common culture media.

\section{Acknowledgements}

Our most sincere thanks to Dr. Rudy Hartskeerl and his team from the Center for reference and research on Leptospirosis, Royal Tropical Institute, Biomedical research, WHO/FAO/OIE, The Netherlands, for their support in typifying the leptospira isolates obtained in our laboratory and their valuable feedback in this manuscript. We also thank the valuable support of Ricardo Vargas and Pedro Banderas from the Experimental Medicine Department, from the Medicine Faculty, UNAM, and the resident doctors from the department of Pathology Anatomy, UNAM-Hospital General de Mexico, and to MS Esther Espindola from the Microscopy Department from the Escuela Nacional de Ciencias Biológicas, IPN, México.

\section{References}

[1] Vinetz, J.M. (2001) Leptospirosis. Current Opinion in Infectious Diseases, 14, 527-538. https://doi.org/10.1097/00001432-200110000-00005

[2] Levett, P.N. (2001) Leptospirosis. Clinical Microbiology Reviews, 14, 296-326. https://doi.org/10.1128/CMR.14.2.296-326.2001

[3] Hartskeerl, R.A., Collares-Pereira, M. and Ellis, W.A. (2011) Emergency, Control and ReEmerging Leptospirosis: Dynamics of Infection in the Changing World. Clinical Microbiology and Infection, 17, 494-501. https://doi.org/10.1111/j.1469-0691.2011.03474.x

[4] Hartskeerl, R.A. (2005) International Leptospirosis Society: Objectives and Achievements. Revista Cubana de Medicina Tropical, 57, 7-10.

[5] Gouveia, E.L., Metcalfe, J., de Carvalho, A.L.F., Aires, T.S.F., Villasboas-Bisneto, J.C., Queirroz, A., et al. (2008) Leptospirosis-Associated Severe Pulmonary Hemorrhagic Syndrome, Salvador, Brazil. Emerging Infectious Diseases, 14, 505-508. https://doi.org/10.3201/eid1403.071064

[6] Velasco-Castrejón, O., Rivas-Sánchez, B. and Rivera-Reyes, H.H. (2008) Leptospirosis Humana Crónica. In: Narro-Robles, J., Rivero, S.O. and López, B.J.J., Eds., Diagnóstico y Tratamiento en la Práctica Médica. El Manual Moderno, 3a Edition, El Manual Moderno, México DF, 765-775.

[7] Velasco-Castrejón, O., Rivas-Sánchez, B., Espinoza, J. and Martinez, H.E. (2007) Diagnóstico de leptospirosis crónica, comparación entre la aglutinación microscópica y 3 técnicas diagnósticas confirmatorias. Revista Cubana de Medicina Tropical, 59. http://www.bvs.sld.cu/revistas/mtr/vol59_1_07/mtr01107.htm

[8] Velasco-Castrejón, O., Rivas-Sánchez, B., Sánchez, S.M.E., Soriano, J., Rivera, R.H.H. and Garibay, F.V. (2009) Leptospirosis crónica en México: diagnóstico microscópico y eviden- 
cias que respaldan su existencia e importancia. Rev Mex Patol Clín, 56, 157-167.

[9] Velasco-Castrejón, O., Rivas-Sánchez, B., Sánchez, S.M.E. and Rivera, R.H.H. (2009) Transición de la leptospirosis aguda a crónica. Seguimiento de siete casos. Rev Mex Patol Clín, 56, 183-192.

[10] World Organization for Animal Health. (2008) Leptospirosis. In: OIE, Ed., Manual of Standards for Diagnostic Test and Vaccines, Office International des Epizooties, Paris, 251-264.

[11] Avdeeva, M.G. (2003) Outcome and Tendency of Late Convalescence in Icterohemorrhagic Leptospirosis. Klin Med (Mosk), 81, 42-47.

[12] Murgatroyd, F. (1973) Chronic Meningitis in Weil's Disease. British Medical Journal, 1, 7-11. https://doi.org/10.1136/bmj.1.3965.7

[13] Hazen, H.H. (1919) Syphilis A Treatise on Etiology, Pathology, Diagnosis, Prognosis, Prophylaxis and Treatment. CV Mosby Company Editors, St. Louis, 647

[14] Pachner, A.R. and Steere, A.C. (1985) The Triad of Neurologic Manifestations of Lyme Disease: Meningitis, Cranial Neuritis and Radiculoneuritis. Neurology, 35, 47-53. https://doi.org/10.1212/WNL.35.1.47

[15] Logigiam, E.L., Kaplan, R.F. and Steere, A.C. (1990) Chronic Neurologic Manifestation of Lyme Disease. The New England Journal of Medicine, 323, 1438-1444. https://doi.org/10.1056/NEJM199011223232102

[16] Hartskeerl, R.A., Smits, H.L., Korver, H., Goris, M.G.A., Terpstra, W.J., Fernández, C., Obregón, A.M., Rodríguez, I., Zamora, Y., Rodríguez, N., Rodríguez, J.E. and Martinez, M.B. (2004) International Course of Laboratory Methods for Diagnosis of Leptospirosis. II Taller Internacional de Leptospirosis, La Habana, Cuba.

[17] Russell, F.B. and Russel, C.J. (1978) Protein-Free and Low-Protein Media for the Cultivation of Leptospira. Infection and Immunity, 19, 562-569.

[18] Te, B.L.A. and Louw, N.H. (1985) Addition of Rabbit Serum to EMJH Medium Improves Isolation of Leptospira Interrogans Serovar Hardjo. The Onderstepoort Journal of Veterinary Research, 52, 53-54.

[19] Bartholomew, J.W. (1981) Stains for Microorganisms in Smears. In: George, C., Ed., Staining Procedures, 4th Edition, Williams \& Wilkins, USA, 409-410.

[20] Javois, L.C. (1999) Immunocytochemical Methods and Protocols. 2nd Edition, Humana Press, USA, Vol. 115, 131-140. https://doi.org/10.1385/1592592139

[21] Tripathy, D.N. and Hanson, L.E. (1974) Immunoperoxidase Staining of Leptospires. Applied Microbiology, 27, 268-269.

[22] WHO-ILS (2003) Human Leptospirosis. Guidance for Diagnosis Surveillance and Control. WHO-ILS. http://www.who.int/csr/don/en/WHO_CDS_CSR_EPH_2002.23.pdf

[23] Ellis, W.A. (1986) The Diagnosis of Leptospirosis in Farm Animals. In: Ellis, W.A. and Little, T.W.A., Eds., The Present State of Leptospirosis Diagnosis and Control, Martinus Nijhoff, Dordrecht, The Netherlands, 13-31.

[24] Brem, S., Gerhads, H., Wollanke, B., Meyer, P. and Kopp, H. (1998) Demonstration of Intraocular Leptospira in 4 Horses Suffering from Equine Recurrent Uveitis (ERU). Berliner und Münchener Tierärztliche Wochenschrift, 111, 415-417.

[25] Faber, N.A., Crawford, M., LeFebure, R., Buyukmihci, N.C., Madigan, J.E. and Willits, N.H. (2000) Detection of Leptospira spp. in the Aqueous Humor Horses with Naturally Acquired Recurrent Uveitis. Journal of Clinical Microbiology, 38, 2731-2733.

[26] McDonough, P.L. (2001) Leptospirosis in Dogs-Current Status. In: Carmichael, L., Ed., 
International Veterinary Information Service, Ithaca, New York.

http://www.ivis.org/advances/Infect_Dis_Carmichael/mcdonough/ivis.pdf

[27] Sackett, D.C. (2003) Canine Leptospirosis Titer Interpretation. Diagnostic Update, 1, 2.

[28] The Leptospirosis Information Center (2009) Persistent Human Leptospirosis. http://www.leptospirosis.org

[29] Romero, E.C., Billerbeck, A.E., Lando, V.S., Camargo, E.D., Souza, C.C. and Yasuda, P.H. (1998) Detection of Leptospira DNA in Patients with Aseptic Meningitis by PCR. Journal of Clinical Microbiology, 36, 1453-1455.

[30] Saengjaruk, P., Chaicumpa, W., Watt, G., Bunyaraksyotin, G., Wuthiekanun, V., Tapchaisri, P., Sittinont, Ch., Panaphut, T., Tomanakan, K., Sakolvaree, Y., Chongsa-Nguan, M., Mahakunkijcharoen, Y., Kalambaheti, T., Naigowit, P., Wambangco, M.A.L., Kurazono, H. and Hayashi, H. (2002) Diagnosis of Human Leptospirosis by Monoclonal Antibody-Based Antigen Detection Urine. Journal of Clinical Microbiology, 40, 480-489.

https://doi.org/10.1128/JCM.40.3.480-489.2002

[31] Ganoza, Ch.A., Matthias, M.A., Saito, M., Cespedes, M., Gotuzzo, E. and Vinetz, J.M. (2010) Asymtomatic Renal Colonization of Humans in the Peruvian Amazon by Leptospira. PLoS Neglected Tropical Diseases, 4, e612. https://doi.org/10.1371/journal.pntd.0000612

[32] Dias-Pinto, J.C. and Rodriguez-Coura, J. (1997) Clinica terapeutica da Doença da Chagas. Edit Fio Cruz, Rio de Janeiro, 486.

[33] Estrada-Parra, S., Velasco-Castrejon, O., Rebora, F., Diaz, M.L. and Padierna, J. (1983) Inmunoterapia de la tuberculosis pulmonar avanzada con factor de transferencia especifico. Salud pública de México, 25, 589-600.

[34] Berrón-Pérez, R., Chavez-Sánchez, R., Estrada-García, I., Espinosa-Padilla, S., Cortéz-Gómez, R., Serrano-Miranda, E., Ondarza-Aguilera, R., Pérez-Tapia, M., Pineda, O.B., JiménezMartínes, M. del C., Portugués, A., Rodríguez, A., Cano, L., Pacheco, P.U., Barrientos, J., Chacón, R., Serafín, J., Mendez, P., Monges, A., Ceravantes, E. and Estrada-Parra, S. (2007) Indications, Usage, and Dosage of Transfer Factor. Revista Alergia México, 54, 134-139.

Submit or recommend next manuscript to SCIRP and we will provide best service for you:

Accepting pre-submission inquiries through Email, Facebook, LinkedIn, Twitter, etc. A wide selection of journals (inclusive of 9 subjects, more than 200 journals)

Providing 24-hour high-quality service

User-friendly online submission system

Fair and swift peer-review system

Efficient typesetting and proofreading procedure

Display of the result of downloads and visits, as well as the number of cited articles Maximum dissemination of your research work

Submit your manuscript at: http://papersubmission.scirp.org/

Or contact ojmm@scirp.org 